\title{
Sporadic isolated congenital asplenia with fulminant pneumococcal meningitis: a case report and updated literature review
}

\author{
Shigeo lijima®o
}

\begin{abstract}
Background: Isolated congenital asplenia (ICA) is a rare and life-threatening condition that predisposes patients to severe bacterial infections. Most of the reported cases are familial and the mode of inheritance is usually autosomal dominant. Here, we report a case of sporadic isolated asplenia and review the literature while focusing on sporadic cases.

Case presentation: We report the case of an 11-month-old female infant who developed fulminant pneumococcal meningitis. The pneumococcal vaccine-unimmunized patient was hospitalized with fever, irritability, and purpura, and was diagnosed as having meningitis, septic shock, and disseminated intravascular coagulation. Streptococcus pneumoniae was isolated from both cerebrospinal fluid and blood. She was successfully treated with prompt antibiotic therapy. During hospitalization, abdominal ultrasonography and computed tomography findings, scintigraphy results, and Howell-Jolly body-containing red blood cells indicated the presence of asplenia without any visceroarterial anomalies. Moreover, the findings of peripheral blood smears and spleen ultrasonographic examinations of her parents were normal.

Conclusions: Majority of sporadic ICA cases were detected only after the onset of overwhelming infection and had a high mortality. In cases of severe invasive pneumococcal disease, a systematic search for Howell-Jolly bodies on blood smears and the presence of asplenia on abdominal imaging are essential for detecting ICA even in the absence of any family history. After the diagnosis of ICA, patient and parent education, vaccinations, antibiotic prophylaxis, and prompt empiric treatment of febrile episode should be provided.
\end{abstract}

Keywords: Sporadic asplenia, Isolated congenital asplenia, Pneumococcal meningitis, Howell-jolly body

\section{Background}

The spleen is critical in the predominantly innate immune response to infections from encapsulated bacterial pathogens such as Streptococcus pneumoniae [1]. Congenital asplenia often occurs as part of a recognized malformation syndrome, with anomalies of the heart, great vessels, and viscera [2]. The best known among these syndromes is the congenital asplenia/polysplenia syndrome associated with visceroarterial heterotaxy; its incidence is estimated at approximately $1 / 10,000$ to $1 / 40,000$ live births [3]. In contrast, isolated congenital asplenia (ICA) occurs less frequently. A recent French nationwide study indicated that the prevalence of ICA is 0.51 per

Correspondence: sige_pd@yahoo.co.jp

Department of Pediatrics, Hamamatsu University School of Medicine, Hamamatsu, Japan million births [3]. Patients with congenital asplenia have increased susceptibility to invasive infections along with a high mortality rate despite aggressive therapy. Although the initial symptoms may be mild and nonspecific, it can progress rapidly to Waterhouse-Friderichsen syndrome with full-blown septic shock and disseminated intravascular coagulation (DIC). Compared to congenital asplenic syndrome, the diagnosis of ICA is more difficult due to the lack of other anomalies. In particular, in sporadic ICA, the condition may remain undetected until the postmortem autopsy.

Here, we present the case of a girl with sporadic ICA who developed overwhelming meningitis due to $S$. pneumoniae and compared the clinical manifestations between sporadic and familial ICA cases by reviewing the literature. 


\section{Case presentation}

A previously healthy 11-month-old female infant (the first child of non-consanguineous Japanese parents) was referred to our hospital with clinical signs of septic shock and purpura, which were preceded by fever for 2 days and signs of upper respiratory tract infection (URI) for 1 week. She had previously received oral antibiotic treatment for the URI. The patient had not received pneumococcal or Haemophilus influenzae type b (Hib) vaccination because these vaccines were not included in the routine immunization program at that time in Japan. On admission, she had a body temperature of $39.4{ }^{\circ} \mathrm{C}$, heart rate of $180 \mathrm{bpm}$, blood pressure of $83 / 46 \mathrm{mmHg}$, and cold extremities with a capillary refill of $>5 \mathrm{~s}$. She was irritable without any focal neurological deficits. She was found to have purpura fulminans with ecchymoses of the face and trunk and purpura of her limbs and ears. Her neck was stiff. Laboratory examination indicated a white blood cell count of $35.1 \times 10^{9} / \mathrm{L}$, with $67 \%$ neutrophils and $25 \%$ lymphocytes; platelet count of $8.1 \times 10^{9} / \mathrm{L}$; hemoglobin level of $10.9 \mathrm{~g} / \mathrm{dL}$; and C-reactive protein level of $18.5 \mathrm{mg} / \mathrm{dL}$. Prolonged prothrombin time and activated partial thromboplastin time and elevated levels of plasma fibrinogen degradation products $(235 \mu \mathrm{g} / \mathrm{mL}$ : normal $<5 \mu \mathrm{g} / \mathrm{mL}$ ) indicated the presence of DIC. A lumbar puncture indicated the presence of pleocytosis in the cerebrospinal fluid (CSF), including 11,527 cells $/ \mu \mathrm{L}$ (95\% polymorphonuclear cells), $11 \mathrm{mg} / \mathrm{dL}$ glucose (blood glucose level; $87 \mathrm{mg} / \mathrm{dL}$ ), and $425 \mathrm{mg} / \mathrm{dL}$ protein. The gram stains of CSF revealed the presence of grampositive diplococci. We diagnosed the patient with bacterial meningitis followed by DIC and treated her with intravenous antibiotics (ampicillin and cefotaxime) empirically and addressed the DIC using anticoagulants. On the day after admission, blood and CSF cultures indicated positive results for $S$. pneumoniae (serotype not available). The minimum inhibitory concentration for penicillin was $<0.06 \mu \mathrm{g} / \mathrm{mL}$. The patient received antibiotic therapy for 14 days with a good clinical response and was discharged without any sequelae.

Over the clinical course, abdominal ultrasonography (US) was performed to detect adrenal hemorrhage as we suspected Waterhouse-Friderichsen syndrome; however, US did not indicate the presence of a spleen (Fig. 1a). In addition, no spleen was visible on abdominal computed tomography (Fig. 1b). Careful blood smear assessment indicated the presence of Howell-Jolly bodies (HJB) (Fig. 1c). Based on the suspicion of asplenia, scintigraphy with Tc-99 m phytate colloid was performed and no functioning splenic tissue was detected (Fig. 1d). The patient had no history of splenectomy. No other malformations such as heart defects, anomalous systemic or pulmonary venous connections, and abdominal heterotaxia were detected, leading to the diagnosis of ICA. Moreover, peripheral blood smears and spleen US examinations of the parents indicated normal results. After that, antibiotic prophylaxis with amoxicillin was initiated as
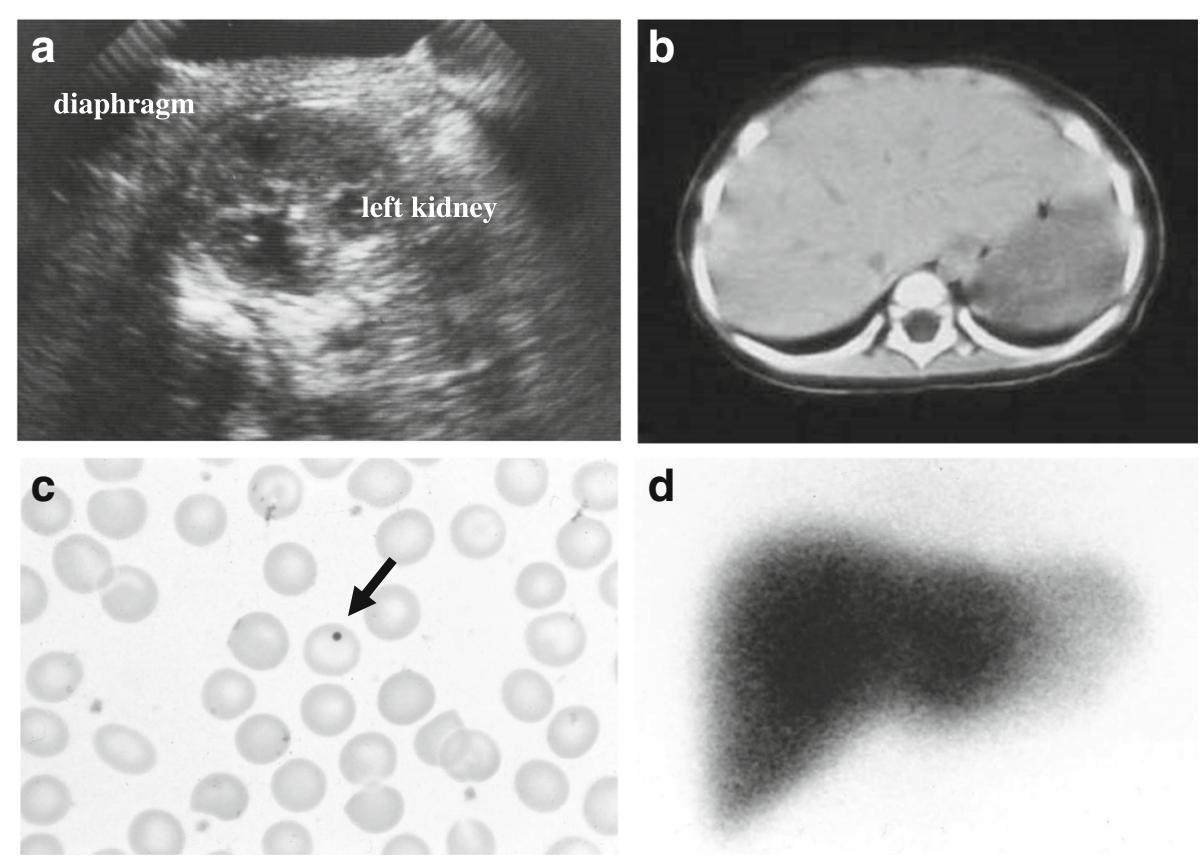

Fig. 1 a Ultrasonography of the abdomen indicating the absence of a spleen; the upper pole of the left kidney is located beneath the diaphragm. b Nonenhanced computed tomography of the abdomen indicating the lack of a spleen on the left. c Peripheral blood smear showing the presence of Howell-Jolly body (arrow). d Scintigraphy with Tc-99 m phytate colloid showing no functional spleen tissue 
well as vaccinations using 7-valent pneumococcal conjugate vaccine (PCV7) and Hib vaccine, followed by 23valent pneumococcal polysaccharide vaccine (PPSV23) when she was 2 years old. The parents were counseled about the need for prompt medical attention after the onset of fever. Subsequently, the patient has not experienced any invasive infections for $>5$ years.

\section{Discussion}

The congenital absence of the spleen has been recognized as a condition for more than 270 years. The first two cases, reported in 1740, were observed independently by Pohl and Jauch; in each of these young adult male cases, absence of the spleen was noted on autopsy [4]. Putschar and Manion described 11 cases (including the two mentioned above) of spleen agenesis without any other malformations in 1956 [4]; to our knowledge, that is the first series on ICA and 70 such patients have been reported to date [5].

In congenital asplenic syndrome, different modes of inheritance have been reported; mostly autosomal recessive, exceptionally autosomal dominant or X-linked. Two human genes are reportedly involved in this syndrome, connexin 43 and ZIC3, which are involved in an $\mathrm{X}$-linked form [6]. On the other hand, most of the reported ICA cases are familial and the mode of inheritance is usually autosomal dominant, although recessive inheritance patterns have also been observed $[3,6]$. Given the isolated abnormality of spleen development, mutations in the Hox 11 have been reported in mice with ICA [7]. Moreover, a recent study in humans with autosomal dominant ICA demonstrated that germline mutations in RPSA lead to a spleen-specific developmental defect [8]. However, the genetic etiology of ICA remains unknown. With respect to sporadic ICA cases, Gilbert et al. described 13 of 31 cases of ICA between 1956 and 2000 [6], and Mahlaoui et al. documented 29 of 65 cases between 1956 and 2009 [3]; these researchers speculated that sporadic cases might be related to either the low penetrance of ICA or de novo mutations. In the present report, we reviewed 73 cases with ICA in the literature between 1956 and 2016 using the Medline database and identified 32 sporadic cases [3, 5, 9-27]. Their clinical details are summarized in Table 1 . The first sign of ICA was severe invasive bacterial infection in 25 of 32 cases (78\%), and 12 patients died. Of the 25 patients, only four had multiple episodes of invasive infections, including two episodes in three cases (two deaths) and three episodes in one case (no death). In a total of $29 \mathrm{ep}-$ isodes of overwhelming sepsis, the causative pathogen was S. pneumoniae in 18 episodes (62\%), $H$. influenzae in six episodes (21\%), and Escherichia coli in two episodes $(7 \%)$. Of the 12 patients who died, at least nine (75\%) died within the first $48 \mathrm{~h}$ of hospital admission and seven (58\%) died within the first $24 \mathrm{~h}$. The mortality rate for overwhelming postsplenectomy infection (OPSI) has been estimated as approximately $50-70 \%$ despite aggressive therapy [28], and $>50 \%$ died within the first $48 \mathrm{~h}$ of hospital admission [29]. Similar to OPSI, overwhelming infection in ICA is a virulent entity that leads to death within 48 years in most cases. Hence, the diagnostic workup should never delay the initiation of empiric antibiotic therapy [30]. A delay of only a few hours may lead to death. Moreover, overwhelming infection in asplenia may also occur at any time after birth and should also be considered in adults, as demonstrated in our case series. As individuals who have undergone splenectomy can be identified as having infection by themselves or by clinicians, some OPSI cases may still be preventable. When asplenia develops as part of heterotaxy syndrome, it is often identified due to the presence of other congenital anomalies, and appropriate management may be instituted to prevent severe infection. However, in the case of ICA, there are no other physical clues for diagnosis and overwhelming infection may be the first sign of the disease [9-11]. In the 73 cases available for review, we compared the clinical characteristics between sporadic and familial ICA using the Mann-Whitney U-test (the Statistical Package for Social Sciences version 23, Tokyo, Japan) (Table 2). The analysis showed that event-free cases were significantly more common in familial ICA $(p=0.001)$. In a familial case, the identification of other family members with the condition may provide an important clue for the diagnosis. However, in sporadic cases, the condition may remain undetected even at the presentation with pneumococcal disease. In the present case, the diagnosis of asplenia in the context of sepsis was confirmed through US of the abdomen and identification of HJB on blood smears. In the case series, HJBs were identified in at least 18 patients (60\%). Abdominal US and HJB assessment are important tests to perform in the first-degree relatives of affected individuals for the diagnosis of asplenia.

As for post-diagnosis management, immunization against encapsulated bacteria is an indispensable strategy to ensure the survival of asplenic patients. Moreover, PCVs enhance immunity in asplenic patients because PCVs can induce antibody responses in the absence of a spleen $[31,32]$. Therefore, in ICA cases, the use of active immunizations including pneumococcal (not only PPSV but also PCV), Hib, and meningococcal vaccines could prevent overwhelming sepsis and save lives [33, 34]. In Japan, Hib conjugate vaccine has been available on a voluntary basis since 2008, and PCV has been available since 2010; however, the vaccination rate was estimated to be $<10 \%$ in those years [35]. Subsequently, these two vaccines have been included in the routine 
Table 1 Reported cases of sporadic congenital isolated asplenia

\begin{tabular}{|c|c|c|c|c|c|c|c|}
\hline Case no. & Age at diagnosis & Sex & Clinical events & Pathogens & Howell-Jolly bodies & Outcome & Reference \\
\hline 1 & 2 months & Female & Meningitis & H. influenzae & Yes & Survived & [13] \\
\hline 2 & 4 months & Unknown & Sepsis & E. coli & NA & Died & [11] \\
\hline 3 & 6 months & Unknown & Sepsis & S. Pneumoniae & NA & Survived & [11] \\
\hline 4 & 6 months & Female & Sepsis, purpura fulminans & Unknown & Yes & Survived & [3] \\
\hline 5 & 7 months & Male & $\begin{array}{l}\text { Sepsis, bilateral adrenal } \\
\text { hemorrhage }\end{array}$ & H. influenzae & NA & Died in $12 \mathrm{~h}$ & [15] \\
\hline 6 & 7 months & Female & Asymptomatic & No infection & Yes & Alive & [3] \\
\hline 7 & 10 months & Unknown & Sepsis & H. influenzae & NA & Survived & [11] \\
\hline 8 & 10 months & Male & Sepsis, purpura fulminans & S. pneumoniae & Yes & Died in $20 \mathrm{~h}$ & [3] \\
\hline 9 & 11 months & Female & Meningitis, purpura fulminans & S. pneumoniae & Yes & Survived & Present case \\
\hline 10 & 12 months & Female & Sepsis, purpura fulminans & S. pneumoniae & Yes & Survived & [3] \\
\hline 11 & 12 months & Male & Meningitis (twice), osteomyelitis & S. pneumoniae & Yes & Survived & [14] \\
\hline 12 & 20 months & Female & Sepsis & Unknown & Yes & Survived & [3] \\
\hline 13 & 21 months & Unknown & Sepsis & S. pneumoniae & NA & Survived & [11] \\
\hline 15 & 1 years & Unknown & Sepsis & S. pneumoniae & NA & Survived & [27] \\
\hline 16 & 2 years & Male & $\begin{array}{l}\text { Sepsis, bilateral adrenal } \\
\text { hemorrhage }\end{array}$ & H. influenzae & NA & Died in $32 \mathrm{~h}$ & [15] \\
\hline \multirow[t]{2}{*}{17} & 2 years & Female & Meningitis (3 times) & E. coli, S. pneumoniae & Yes & Survived & [5] \\
\hline & & & & H. influenzae & & & \\
\hline 18 & 3 years & Unknown & Sepsis & H. influenzae & NA & Died in $24 \mathrm{~h}$ & [11] \\
\hline 19 & 4 years & Female & $\begin{array}{l}\text { Sepsis, bilateral adrenal } \\
\text { hemorrhage }\end{array}$ & S. pneumoniae & NA & Died in $12 \mathrm{~h}$ & [18] \\
\hline 20 & 5 years & Male & Sepsis, meningitis & S. pneumoniae & NA & Died & [23] \\
\hline 21 & 10 years & Female & Sepsis, arthritis (twice) & S. pneumoniae & NA & Died in $24 \mathrm{~h}$ & [21] \\
\hline 22 & 15 years & Male & $\begin{array}{l}\text { Meningitis (twice), bilateral } \\
\text { adrenal hemorrhage }\end{array}$ & S. pneumoniae & Yes & Died in $3 \mathrm{~h}$ & [12] \\
\hline 23 & 28 years & Male & Sepsis & Group B streptococcus & Yes & Survived & [24] \\
\hline 24 & 20 years & Male & Tonsillitis & Unknown & Yes & Alive & [22] \\
\hline 25 & 36 years & Male & $\begin{array}{l}\text { Meningitis, bilateral adrenal } \\
\text { hemorrhage }\end{array}$ & S. pneumoniae & NA & Died in $29 \mathrm{~h}$ & [10] \\
\hline 26 & 37 years & Female & Thrombocytosis & No infection & Yes & Alive & [16] \\
\hline 27 & 44 years & Female & Thrombocytosis & No infection & Yes & Alive & [25] \\
\hline 28 & 56 years & Female & Thrombocytosis & No infection & Yes & Alive & [20] \\
\hline 29 & 56 years & Male & Thrombocytosis & No infection & Yes & Alive & [20] \\
\hline 30 & 60 years & Female & Meningitis & S. pneumoniae & Yes & Survived & [19] \\
\hline 31 & 67 years & Female & Sepsis & S. pneumoniae & NA & Died in $24 \mathrm{~h}$ & [26] \\
\hline 32 & 72 years & Male & Thrombocytosis & No infection & Yes & Alive & [28] \\
\hline
\end{tabular}

NA Not available

immunization program since 2013. In fact, the present patient did not receive the PCV or Hib vaccine before the septicemic onset because these vaccinations were voluntary at the time. Moreover, meningococcal vaccine has not been approved yet in Japan. In contrast, in Western countries, greater efforts, including the publication of national guidelines, have been made to improve the management of asplenic patients [33, 34]. As for the latest recommendations, asplenic patients should receive vaccines including 13-valent PCV (PCV13) and Hib vaccine for children aged $<2$ years as recommended routinely for immunocompetent persons based on the Centers for Disease Control and Prevention annual schedule, followed by PPSV23 at 2 years of age or older, with a recommendation for a second dose of PPSV23 5 years later. Moreover, some European public health agencies recommend PPSV23 reimmunization of asplenic individuals every 5 years [36]. Meningococcal vaccine 
Table 2 Comparison of clinical characteristics between sporadic and familial cases of isolated congenital asplenia

\begin{tabular}{|c|c|c|c|}
\hline & Sporadic $n=32$ & Familial $n=41$ & $P$ value \\
\hline Age at diagnosis, years & $2.1(0.8-34.2)$ & $1.0(0.6-3.0)$ & 0.04 \\
\hline Male sex & $11^{a}(44)$ & $25(61)$ & 0.18 \\
\hline \multicolumn{4}{|l|}{ Clinical events } \\
\hline Sepsis and/ or meningitis & $25(78)$ & $24(58)$ & 0.08 \\
\hline Others & $6(19)$ & $2(5)$ & 0.06 \\
\hline Asymptomatic & $1(3)$ & $15(37)$ & 0.001 \\
\hline \multicolumn{4}{|l|}{ Pathogens } \\
\hline S. pneumoniae & $16^{\mathrm{b}}(62)$ & $14^{c}(56)$ & 0.69 \\
\hline H. influenzae & $5^{\mathrm{b}}(19)$ & $3^{c}(12)$ & 0.48 \\
\hline Others & $3^{b}(12)$ & $0^{c}(0)$ & 0.08 \\
\hline Howell- Jolly bodies & $18(56)$ & $17(41)$ & 0.21 \\
\hline \multicolumn{4}{|l|}{ Outcome } \\
\hline Death & $12(38)$ & $16(39)$ & 0.68 \\
\hline
\end{tabular}

Values are presented as median (interquartile range) or number (percentage). $P<0.05$ is considered to be significant. ${ }^{\text {a data }}$ from 25 patients were available.

${ }^{b}$ data from 26 patients were available. ${ }^{c}$ data from 25 patients were available

should also be administered to asplenic patients aged $\geq 2$ months. In addition, yearly influenza vaccination is recommended for all asplenic patients aged $>6$ months because the influenza virus is an important risk factor for secondary pneumococcal and $H$. influenzae infections [34]. However, vaccination does not fully eliminate the risk of invasive infection [32]. The second major strategy is antibiotic prophylaxis and treatment. Daily antibiotic prophylaxis against pneumococcal infections is recommended due to evidence of good efficacy in patients with sickle cell anemia (functional asplenia) $[37,38]$. However, the appropriate duration of prophylaxis in asplenic patients is unknown. The use of life-long penicillin prophylaxis has potential disadvantages as it can be associated with the development of bacterial resistance, may have side effects including allergy, and may be associated with poor adherence [39]. The American Academy of Pediatrics recommends prophylaxis until the child is 5 years of age [38]. In contrast, British guidelines recommend life-long penicillin prophylaxis in high-risk patients defined as those $<16$ or $>50$ years of age, those with an inadequate serological response to pneumococcal vaccination, and those who have had a previous episode of invasive pneumococcal disease [34]. Education for asplenic patients and their parents is also important to enable them to understand that all febrile illnesses are potentially serious in asplenic patients and that patients developing such signs must be given systemic antibiotics and admitted to hospital. If an asplenic patient travels to or resides in an area where medical care is not accessible, an appropriate antibiotic agent should be readily available and the child's caregiver should be instructed in its appropriate use [38]. Patients and parents should also be advised about animal handling as overwhelming sepsis (due to Capnocytophaga canimorsus) may result from dog, cat, or other animal bites [40]. Furthermore, these patients require specific advice regarding travel as they are at increased risk of severe malaria (mosquito bites) and babesiosis (tick bites) in endemic areas $[34,38]$.

\section{Conclusions}

In the case of severe invasive pneumococcal disease, a systematic search for HJB on blood smears and imaging examination of the abdomen for the presence of asplenia are vital for detecting ICA, even in the absence of a family history. If asplenia is detected, life-saving vaccination with a series of PCV13 and Hib vaccines, followed by PPSV23, in addition to penicillin prophylaxis, preemptive investigation, and empiric treatment early in the course of illnesses should be provided.

Considering the limitations of the literature review, this article may have incomplete data about the full syndrome of asplenia. The inclusion of unwritten, unpublished, or repetitive cases, or cases published in grey literature might have influenced the findings.

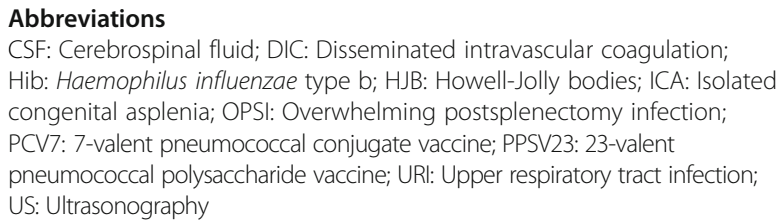

Acknowledgements

Not applicable.

Funding

No funding sources.

Availability of data and materials

All data supporting the findings are within the manuscript.

Authors' contributions

SI conceived the study and was responsible for data collection. SI performed data analysis, interpreted the data, and prepared the first draft of the manuscript.

Ethics approval and consent to participate

Our ethics committee waived the requirement of ethics approval because all medical and laboratory procedures are routinely carried out and do not affect decisions concerning treatment.

Consent for publication

A written informed consent was obtained from the patient's parents for publication of this case report and any accompanying images.

Competing interests

The authors declare that they have no competing interests.

\section{Publisher's Note}

Springer Nature remains neutral with regard to jurisdictional claims in published maps and institutional affiliations. 
Received: 5 June 2017 Accepted: 10 December 2017

Published online: 18 December 2017

\section{References}

1. Bisno AL, Freeman JC. The syndrome of asplenia, pneumococcal sepsis, and disseminated intravascular coagulation. Ann Int Med. 1970;72:389-93.

2. Ivemark BI. Implications of agenesis of the spleen on the pathogenesis of controtruncus anomalies in childhood; an analysis of the heart malformations in the splenic agenesis syndrome, with fourteen new cases. Acta Paediatr. 1955;44(Supple 104):7-110.

3. Mahlaoui N, Minard-Colin V, Picard C, Bolze A, Ku CL, Tournilhac O, et al. Isolated congenital asplenia: a French nationwide retrospective survey of 20 cases. J Pediatr. 2011:158:142-8.

4. Putschar WGJ, Manion WC. Congenital absence of the spleen and associated anomalies. Am J Clin Pathol. 1956:26:429-70.

5. Uchida Y, Matsubara K, Wada T, Oishi K, Morio T, Takada H, et al. Recurrent bacterial meningitis by three different pathogens in an isolated asplenic child. J Infect Chemother. 2012;18:576-80

6. Gilbert B, Menetrey C, Belin V, Brosset P, de Lumley L, Fisher A. Familial isolated congenital asplenia: a rare, frequently hereditary dominant condition, often detected too late as a cause of overwhelming pneumococcal sepsis. Report of a new case and review of 31 others. Eur J Pediatr. 2002;161:368-72.

7. Roberts CW, Shutter JR, Korsmeyer SJ. Hox11 controls the genesis of the spleen. Nature. 1994;368:747-9.

8. Bolze A, Mahlaoui N, Byun M, Turner B, Trede N, Ellis SE, et al. Ribosomal protein SA haploinsufficiency in humans with isolated congenital asplenia. Science. 2013;340:976-8.

9. Myerson RM, Koelle WA. Congenital absence of the spleen in an adult: report of a case associated with recurrent Waterhouse-Friderichsen syndrome. N Engl J Med. 1956;254:1131-2.

10. Waldman JD, Rosenthal A, Smith AL, Shurin S, Nadas AS. Sepsis and congenital asplenia. J Pediatr. 2002;90:555-9.

11. Gopal V, Bisno AL. Fulminant pneumococcal infections in "normal" asplenic hosts. Arch Intern Med. 1977:137:1526-30.

12. Honingman $R$, Lanzkowsky P. Isolated congenital asplenia: an occult case of overwhelming sepsis. Am J Dis Child. 1979;133:552-3.

13. Gill DG, Kara M. Septicaemia and adrenal hemorrhage in congenital asplenia. Arch Dis Child. 1991;66:1366.

14. Dyke MP, Martin RP, Berry PJ. Septicaemia and adrenal haemorrhage in congenital asplenia. Arch Dis Child. 1991;66:636-7.

15. Rose C, Quesnel B, Facon T, Fenaux P, Jouet JP, Bauters F. Congenital asplenia, a differential diagnosis of essential thrombocythemia. Presse Med. 1993;22:1748.

16. Ferlicot S, Emile JF, Le Bris JL, Cheron G, Brousse N. Congenital asplenia. A childhood immune deficit often detected too late. Ann Pathol. 1997:17:44-6.

17. Kanthan R, Moyana T, Nyssen J. Asplenia as a cause of sudden unexpected death in childhood. Am J Forensic Med Pathol. 1999:20:57-9.

18. Germing U, Perings C, Steiner S, Peters AJ, Heintzen MP, Aul C. Congenital asplenia detected in a 60-year-old patient with septicemia. Eur J Med Res. 1999;4:283-5.

19. Chanet V, Tournilhac O, Dieu-Bellamy V, Boiret N, Spitz P, Baud O, et al. Isolated spleen agenesis: a rare cause of thrombocytosis mimicking essential thrombocythemia. Haematologica. 2000;85:1211-3.

20. Halbertsma FJJ, Neeleman C, Weemaes CM, van Deuren M. The absent and vanishing spleen: congenital asplenia and hyposplenism-two case reports. Acta Paediatr. 2005:94:369-71.

21. Almoznino-Sarafian D, Dotan E, Sandbank J, Gorelik O, Chachashvily S, Shteinshnaider M, et al. Unusual manifestations of myelofibrosis in a patient with congenital asplenia. Acta Haematol. 2007;118:226-30.

22. Araújo AR, Maciel I, Lima L, Chacim I, Barbot J. Congenital asplenia and severe visceral toxocariasis. Pediatr Infect Dis J. 2008;27:478.

23. Thiruppathy K, Privitera A, Jain K, Gupta S. Congenital asplenia and group B streptococcus sepsis in the adult: case report and review of the literature. FEMS Immunol Med Microbiol. 2008;53:437-9

24. Takahashi F, Uchida K, Nagaoka T, Honma N, Cui R, Yoshioka M, et al. Isolated congenital spleen agenesis: a rare cause of chronic thromboembolic pulmonary hypertension in an adult. Respirology. 2008:13:913-5.

25. Vincentelli C, Molina EG, Robinson MJ. Fatal pneumococcal WaterhouseFriderichsen syndrome in a vaccinated adult with congenital asplenia. Am J Emerg Med. 2009;27:751.e3-5.
26. Shachor-Meyouhas $Y$, Sprecher H, Kassis I. Isolated congenital asplenia-a rare cause of severe pneumococcal sepsis. Harefuah. 2010;149:486-9.

27. Imashuku S, Kudo N, Kubo K, Takahashi N, Tohyama K. Persistent thrombocytosis in elderly patients with rare hyposplenias that mimic essential thrombocythemia. Int J Hematol. 2012;95:702-5.

28. Okabayashi T, Hanazaki K. Overwhelming postsplenectomy infection syndrome in adults-a clinically preventable disease. World J Gastroenterol. 2008;14:176-9.

29. Brigden ML, Pattullo AL. Prevention and management of overwhelming postsplenectomy infection-an update. Crit Care Med. 1999;27:836-42.

30. Lynch AM, Kapila R. Overwhelming postsplenectomy infection. Infect Dis Clin N Am. 1996;10:693-707.

31. Breukels MA, Zandvoort A, van Den Dobbelsteen GP, van Den Muijsenberg A, Lodewijk ME, Beurret $M$, et al. Pneumococcal conjugate vaccines overcome splenic dependency of antibody response to pneumococcal polysaccharides. Infect Immun. 2001;69:7583-7.

32. Forstner C, Plefka S, Tobudic S, Winkler HM, Burgmann K, Burgmann H. Effectiveness and immunogenicity of pneumococcal vaccination in splenectomized and functionally asplenic patients. Vaccine. 2012;30:5449-52.

33. Rubin LG, Levin MJ, Ljungman $P$, Davies EG, Avery $R$, Tomblyn M, Bousvaros A, Dhanireddy S, Sung L, Keyserling H, Kang I. Infectious Diseases Society of America. 2013 IDSA clinical practice guideline for vaccination of the immunocompromised host. Clin Infect Dis. 2014;58:309-18.

34. Davies JM, Lewis MP, Wimperis J, Rafi I, Ladhani S, Bolton-Maggs PH. British Committee for Standards in Haematology. Review of guidelines for the prevention and treatment of infection in patients with an absent or dysfunctional spleen: prepared on behalf of the British Committee for Standards in Haematology by a working party of the Haemato-oncology task force. Br J Haematol. 2011;155:308-17.

35. Ishiwada N, Hishiki H, Nagasawa K, Naito S, Sato Y, Chang B, et al. The incidence of pediatric invasive Haemophilus influenzae and pneumococcal disease in Chiba prefecture, Japan before and after the introduction of conjugate vaccines. Vaccine. 2014:32:5425-31.

36. Mourtzoukou EG, Pappas G, Peppas G, Falagas ME. Vaccination of asplenic or hyposplenic adults. Br J Surg. 2008:95:273-80

37. Hirst C, Owusu-Ofori S. Prophylactic antibiotics for preventing pneumococcal infection in children with sickle cell disease. Cochrane Database Syst Rev. 2014;11:CD003427.

38. American Academy of Pediatrics. Children with asplenia or functional asplenia. In: Kimberlin DW, Brady MT, Jackson MA, Long SS, editors. Red book: 2012 report of the committee on infectious diseases. 29th ed. Elk Grove Village, IL: American Academy of Pediatrics; 2012. p. 88-90.

39. Keenan RD, Boswell T, Milligan DW. Do post-splenectomy patients take prophylactic penicillin? Br J Haematol. 1999:105:509-10.

40. Zajkowska J, Król M, Falkowski D, Syed N, Kamieńska A. Capnocytophaga canimorsus - an underestimated danger after dog or cat bite - review of literature. Przegl Epidemiol. 2016;70:289-95.

\section{Submit your next manuscript to BioMed Central and we will help you at every step:}

- We accept pre-submission inquiries

- Our selector tool helps you to find the most relevant journal

- We provide round the clock customer support

- Convenient online submission

- Thorough peer review

- Inclusion in PubMed and all major indexing services

- Maximum visibility for your research

Submit your manuscript at www.biomedcentral.com/submit
) Biomed Central 